Comunicología y descolonización. Una lectura histórica para nuevas mediaciones en la era digital Francisco Sierra Caballero

Tram[p]as de la Comunicación y la Cultura, dossier temático, e053, 2021

ISSN 2314-274X | https://doi.org/10.24215/2314274xe053

http:// perio.unlp.edu.ar/ojs/index.php/trampas

FPyCS | Universidad Nacional de La Plata

La Plata | Buenos Aires | Argentina

\title{
COMUNICOLOGÍA Y DESCOLONIZACIÓN
}

\section{UNA LECTURA HISTÓRICA PARA NUEVAS MEDIACIONES \\ EN LA ERA DIGITAL \\ COMUNICOLOGY AND DECOLONIZATION:}

A HISTORICAL READING FOR NEW MEDIATIONS

IN THE DIGITAL AGE

Francisco Sierra Caballero

fsierra@us.es

https://orcid.org/0000-0001-7398-7588

Universidad de Sevilla | España

\section{Resumen}

El presente artículo expone un análisis que vincula la historia de la comunicación en las ciencias sociales a partir de la obra de Dorfman y de Mattelart desde su origen a la era digital. Asimismo, a partir de los conceptos de mediación social, comunicación, colonización y democracia propone pensar las luchas politicas y culturales que tuvieron lugar desde la publicación de la primera edición de Para leer al Pato Donald (1971), para concluir con algunas lecciones de utilidad para el presente-futuro.

\section{Abstract}

This article presents an analysis that links the history of communication in the social sciences based on the work of Dorfman and Mattelart from its origin to the digital age. Likewise, starting from the concepts of social mediation, communication, colonization and democracy, it proposes to think about the political and cultural struggles that took place since the publication of the first edition of Para leer al Pato Donald (1971), to conclude with some useful lessons for the present-future.

Palabras clave | comunicología, descolonización, ciencias sociales, era digital

Keywords | communicology, decolonization, social sciences, digital age

Recibido: 21/10/2021 | Aceptado: 22/11/2021 | Publicado: 15/12/2021 


\title{
COMUNICOLOGÍA Y DESCOLONIZACIÓN
}

\author{
UNA LECTURA HISTÓRICA PARA NUEVAS \\ MEDIACIONES EN LA ERA DIGITAL
}

\author{
Por Francisco Sierra Caballero
}

\section{Introducción}

Advertía Pierre Bourdieu que un problema común en ciencias sociales es la excesiva distancia o, por el contrario, el exceso de proximidad. En tiempos de la complicidad sumisa, de una ciencia complaciente con la lógica del valor o, en general, oportunista -una suerte de renuncia o de resignación propia del neopositivismo y la investigación administrativa-, aproximarnos a un clásico que movió los cimientos del orden instituido de la mediación social es más una necesidad que una obligación moral o un deber ético, si, por norma, como se presupone a toda actividad científica, hemos de comprender el mundo que habitamos.

Esta exigencia es hoy objeto de cuestionamiento, pese a que no hay mediación cognitiva consistente que no presuponga la reflexividad. Pensar la práctica teórica no es otra cosa, en fin, que garantizar la validez y el alcance de las respuestas formulando preguntas que aborden el núcleo central de la reproducción social, conscientes de los limites, de la posición de observación y del marco histórico que ancla toda enunciación. Solo así podemos cumplir el precepto marxiano de liberarnos completamente de las posiciones de sujeción que se despliegan en nuestra contemporaneidad en forma de redes de captura 
de sentido, eludiendo analizar, relacionalmente, la estructura de poder en la que estamos insertos. Por ello, es tan importante hoy volver a la historia y, en forma de contrapunto, revisitar procesos, luchas y debates que puedan ayudarnos a transformar la cuarta revolución industrial democratizando el capitalismo de plataformas. Hoy que el campo simbólico es atravesado por la guerra cultural en medio de la crisis terminal del capitalismo conviene formular una lectura, en este sentido, de las luchas que fueron para concluir algunas lecciones de utilidad para el presente-futuro.

Sabemos que el trabajo de Dorfman y Mattelart, en el seno de los debates político-culturales que generaba la "vía chilena al socialismo", sintetizaba la perspectiva teórico-metodológica con la que los autores abordaban la lectura ideológica de las historietas de Disney con la idea de sentar las bases para abordar la crítica del papel de la comunicación de masas en lo que se llamaba la "batalla ideológica". Puesto que, conceptualmente, ideología y cultura formaban parte del mismo campo social de la mediación simbólica, esta batalla se concebía como parte del proyecto histórico de transformación de la vida cotidiana. Desde este punto de vista, Schmucler expresaba su recelo hacia -escribía- una "izquierda mostrenca desanimada" que postergaba toda iniciativa concreta en el plano cultural en nombre de otras prioridades como la transformación de la economía o del aparato de Estado.

En el editorial del número uno de la revista Comunicación y Cultura, el objetivo quedaba meridianamente claro: abrir un proceso de articulación para la liberación de los pueblos de América Latina. A partir de esta lucha, no exenta de contradicciones, debían emerger los gérmenes de una nueva teoría y una nueva práctica de la comunicación que, como razonara Hugo Assmann a propósito del papel de la ciencia en esta disputa, se construyera con un nuevo modo social de producir la vida hasta aspectos más intimos de la cotidianeidad del hombre. En este marco politico de lucha por la emancipación contra el imperialismo cultural hay que situar, en el contexto chileno, publicaciones como Agresión desde el espacio o La industria cultural no es una industria ligera (Casa de las Américas, La Habana, 1973) y artículos como el que publica el número uno de la revista Comunicación y Cultura sobre contrarrevolución cultural y la penetración ideológica en la educación de series pedagógicas como Barrio Sésamo, promovidas por la UNESCO y la 
Fundación Ford. Como ha analizado en detalle Mariano Zarowsky, no es exagerado leer el prólogo de Schmucler como una carta de presentación de la colección Comunicación de Masa en siglo XXI. Encontramos allí una idea sugerente y paradojal respecto de la función que imaginaba para el libro de Dorfman y Mattelart, pero también, como observa Zarowsky, más allá, para todo libro en cuanto artefacto cultural. Su éxito [anotaba siguiendo el planteo de los propios autores] [...] estará logrado cuando, negándose a sí mismo como objeto, pueda ayudar a una práctica social que lo borre, reescribiéndolo en una estructura distinta que ofrezca al hombre otra concepción de su relación con el mundo (Schmucler, en Dorfman \& Mattelart, 1978, p. 8).

\begin{abstract}
Esta apelación a la acción del lector, de quien se esperaba reescribiera el libro bajo nuevas coordenadas, era afin a las ideas de un movimiento de vanguardia que entonces y en distintos campos -crítica literaria, novela, plástica y con intensidad en el cine- aspiraban a poner en cuestión la relación tradicional entre autores y público a partir de una concepción transformada de las formas pero también de los propios soportes materiales de expresión y circulación de las obras (Zarowsky, 2020, p. 90).
\end{abstract}

El objetivo, como sabemos, fue alcanzado en parte. Ya para 1974 se había llegado a la doceava edición. Entre 1972 y 1973, nuevos títulos siguieron la estela del éxito del volumen de Dorfman y de Mattelart incorporando autores como Octavio Getino, Fernando Solanas e incluso antologías de Lenin sobre el problema de la ideología. "La colección se desplegaba así a toda marcha en un periodo intenso y vertiginoso de la vida política argentina y latinoamericana" (Zarowsky, 2020, p. 91).

En el contenido de La ideología de la dominación en una sociedad dependiente pero sobre todo en la serie de reseñas e intercambios publicados [...] se puede seguir la afinidad entre las posiciones teóricas de Mattelart y Schmucler tanto como la génesis de una red de colaboración transnacional que conectaba grupos académicos $\mathrm{y}$ formaciones culturales, proyectando la circulación de textos, autores y perspectivas hacia un espacio de alcance latinoamericano. La actividad editorialista de Schmucler, de Los Libros a Signos y luego Siglo XXI, funcionaba (en este sentido) como polo de atracción e irradiación (Zarowsky, 2019, p. 24). 
El legado de estos debates y el modo en el que se articuló el frente cultural es un referente ejemplar que puede arrojarnos luz sobre cómo confrontar el poder omnímodo del capitalismo de plataformas. Como antaño, vivimos un momento de emergencia del antagonismo y el retorno a Marx para desplegar una crítica económico-política de la comunicación, conformándose incluso una red transnacional de investigadores, redes y colectivos subalternos dispuestos a impugnar el modo dominante de mediación desde el sur global. Sería desde luego discutible equiparar ambos procesos o momentos históricos, por las notables y considerables diferencias. De ello hemos discutido ampliamente en ULEPICC. Ahora, lo que no cabe duda es que Para leer el Pato Donald proyecta, anticipatoriamente, bases de análisis y crítica cultural que aún resultan plenamente operativos por lo que todo proyecto de crítica de la mediación social debe tomar en cuenta a la hora de confrontar la batalla ideológica cuando menos cinco tesis que sugiere dicho trabajo.

\section{Lecciones de la critica contra Disney}

\section{Tesis I. Toda crítica de la mediación ha de partir de la crítica}

del fetichismo de la mercancía y del principio de universal equivalencia que rige en la producción cultural mediatizada.

Un primer aporte de Para leer el Pato Donald es que puso en evidencia la politicidad de la mediación, la intencionalidad de la representación de Disney, un mundo mágico, embrujado, fantástico que reproduce el orden social según la ley de hierro de la acumulación del capital. Tal y como se puede colegir de la lectura del ensayo en las páginas 6, 14 u 88 del libro, el análisis del montaje cultural de Disney demuestra el carácter circular de las historietas, lo que refuerza el discurso de la invariabilidad de lo social real. Desde este punto de vista, el ensayo de Ariel y Armand pone en evidencia que, en lo esencial, la disneylandización es la dinerización como proyecto (pp. 85, 88 y 89). La única aventura posible es la de la circulación de las mercancías y el capital. El avatar del dinero como proyecto. «El mundo es centripeto, introvertido, ególatra: el paroxismo del individuo-isla. Es una soledad que no quiere admitir su condición de tal” (Dorfman \& Mattelart, 1978, p. 37). Por ello, se nos representa en Disney un mundo estático que anticipa, décadas antes, el discurso del fin de 
la historia de Fukuyama o el discurso TINA de Thatcher. El imperio de la razón unidimensional marca así pues un horizonte de progreso mediatizado por la fantasía de la mercancía realizada, por la cosificación permanente de actores que no tienen vida productiva. Hay comercio, goce, aventuras, nunca cotidianeidad materializada en lo concreto. El mito del selfman, a lo Trump, es complementario en este punto del relato de repetición de lo mismo, a fin de simular cierta épica en la anodina historia de repetición de lo mismo (Dorfman $\&$ Mattelart, 1978, p. 120)

\section{Tesis II. La crítica de la mediación social dominante exige}

la deconstrucción de la estereotipia y la colonialidad interna

y, en general, de la colonialidad del saber-poder mediatizado.

Como comentara en su calidad de editor y de académico Schmucler en la edición de 1978 (la número 18 por entonces), el ensayo es un "instrumento claramente político que denuncia la colonización cultural común a todos los países latinoamericanos. De allí su tono parcial y polémico, la discusión apasionada que recorre sus páginas, su declarada vocación de ser útil que le hace prescindir de preciosismos eruditos" (Schmucler en Dorfman \& Mattelart, 1978, p. 7). Para ello, como reconocen los autores en la edición posterior (p. 53) que se maneja para este artículo, se tachó incluso a ambos de cultivar el marxismo ficción, como facinerosos forasteros que introducen ideas contrarias a la cultura nacional que la prensa dominante identificaria con los de la industria Disney. En este sentido, un objetivo estratégico de este libro pionero fue desnaturalizar el imaginario colonizado tanto del entretenimiento infantil como de la mediación de la industria USA de exportación cultural como un problema de colonización de las conciencias. Desde este punto de vista, el libro, como concluye el profesor Zarowsky (2019) en sus estudios sobre la historia intelectual de este periodo, representa un proyecto de construcción de frente cultural y contrahegemonía, a partir de

[...] la colección Comunicación de Masa, una serie orientada por Héctor Schmucler en la editorial Siglo XXI Argentina entre 1972 y 1973. Desde el prisma de la historia intelectual nos interrogamos por las prácticas editorialistas de los principales promotores de los estudios en comunicación y cultura en América Latina. La perspectiva contribuye a 
dar cuenta de las condiciones sociales de emergencia de este campo de saberes tanto como la participación de este conjunto de discursos especializados en un universo político-cultural más amplio (Zarowsky, 2019).

Más aún, la colección Comunicación de Masa pone de relieve una serie de fenómenos y de procesos: la existencia de una red transnacional que conectaba en el período formaciones culturales emergentes (en la que Schmucler oficiaba como promotor y articulador. Y que implicaba un cuestionamiento de paso de la colonialidad de la Comunicología, no solo por el objeto y crítica del imperialismo cultural, sino también por la forma de pensar y construir pensamiento en común. Ya en otro estudio pusimos de relieve la importancia del ensayo en América Latina para pensar el barroco y la americanización. La tesis de Bolivar Echeverría podría ser, de hecho, aplicado, en este punto, como una lección para vindicar la emergencia de un pensamiento otro hoy que avanza y se impone de forma absoluta el pensamiento administrativo y la investigación neopositivista (Sierra, 2019).

\section{Tesis III. La crítica de la ideología debe ser complementada} por una lectura geopolítica de la comunicación y el imperialismo cultural.

El universo Disney analizado nos muestra una clara división internacional del trabajo, metamorfoseado en la historieta en el contrapunto de trueque y acumulación de oro y la superioridad técnica de la metrópoli. Aquí el brutalismo no es un estilo arquitectónico, sino una representación de espacios y paisajes, además de personajes, por el que se proyecta, en forma de gigantismo el poder del cuerpo de los salvajes dominados, como síntoma del destino manifiesto por el que han de ser naturaleza pura, energía física de explotación y extracción de la riqueza natural autóctona. La cultura del despojo es diseccionada punto por punto con ejemplos por Dofman y Mattelart ilustrando cómo se educa a los buenos salvajes en el espejo del futuro que representa el poder colonizador. El problema es que normalmente la letra con sangre entra. Napalm y comics, esta es la cuestión. La intervención sobre Vietnam, Cuba y la actualidad de los conflictos internacionales forma parte de la trama discursiva de la revista Disney en todo momento como hoy lo hace sin fisuras discursivas el audiovisual o la industria del videojuego (Dorfman \& 
Mattelart, 1978, p. 73). De ahí la conveniencia de la crítica del imperialismo cultural y, desde luego, del análisis geopolítico de la comunicación, considerando el papel de la tecnología como medio de civilización y colonialidad, eterno retorno de la dominación presente como civilización, en la línea que se expone Americanismo y dominación. (p.158) siguiendo la lectura que la teoría de la dependencia formularía con autores como Celso Furtado.

\section{Tesis IV. Todo proyecto cultural alternativo exige desplegar}

\section{un análisis del objeto de la crítica de la información a la interacción} mediatizada, en un sentido amplio.

Mattelart y Dorfman tuvieron el acierto de asumir una estrategia de dilución con al menos dos desplazamientos: de la crítica de la ideología de la noticia a pensar el ocio y entretenimiento y del análisis de la refracción ideológica de la información de actualidad sobre los adultos a pensar la formación de los ciudadanos abordando la recepción infantil. Ello se tradujo fundamentalmente en una crítica a la academia y la comunicología al cuestionar el desconocimiento y la forma disyuntiva del trabajo intelectual que vive su función separada de los procesos de transformación social. El principio de inversión del animalario Disney presupone justamente esta lógica de proyección imaginaria de las contradicciones de un universo destinado a repetir lo previsible. Sucede en la arcadia perdida de la naturaleza (dialéctica del campo y la ciudad) y provee de repertorios simbólicos destinados a la reificación de lo común. En palabras de los autores, "para acceder al conocimiento, que es una forma de poder, no podemos seguir suscribiendo, con la vista y la lengua vendadas, los rituales de interacción con que las sacerdotisas de la espiritualidad protegen y legitimizan sus derechos, exclusivos, a pensar y a opinar" (Dorfman \& Mattelart, 1978, p. 10). Esta es la función del Seminario de Subliteratura y modo de Combatirla del CEREN que da origen al ensayo y es una cuestión que ha recorrido a lo largo de su obra la reflexión de Armand Mattelart de forma más que productiva y pertinente. 


\section{Tesis V. La crítica de la mediación, como toda teoría crítica}

\section{de la comunicación, ha de asumir por norma el principio de transversalidad} y establecer conectores ideológicos de distintos ámbitos de la vida cotidiana.

Ahora que tanto se reflexiona sobre la interseccionalidad, tiene en este como en otros ejemplos de la década de los setenta antecedentes revolucionarios que articulan la crítica de la representación de clase con la igualdad de género y de raza (p. 77). Estos aprendices de brujo, "el peligroso ratón" como analizara en su libro del mismo título Henry Giroux, tiene una clara intencionalidad en la lucha de clases. La representación individualizada, y casi de aislamiento, de los protagonistas alimenta la visión dominante de la burguesía y no solo en el discurso de la caridad y de la cooperación instrumental, sino en forma de competencia encarnizada similar a la de los personajes de Brecht en Santa Juana de los Mataderos. La clase obrera aparece difuminada, invisible, anticipando en parte el discurso administrativo de la sociedad postindustrial a lo Daniel Bell. El relato es un relato sin historia. Al tiempo se da una imagen patologizada de toda insurgencia o propuesta revolucionaria (Dorfman \& Mattelart, 1978, p. 96). Por ello el ensayo cuestiona la imagen idílica de la infancia como un espacio ahistórico, universal que, heredada de la literatura infantil, nos muestra a los niños siempre inmaculados, espontáneos, bondadosos, un espacio mágico sin conflictos ni violencia, más propia del mundo adulto, ausente en parte en la representación de la revista Disney. En definitiva, fieles a la máquina de Skinner (parodiada por Bart Simpsom en la actualidad),

\footnotetext{
los adultos crean un mundo infantil donde ellos puedan reconocer y confirmar sus aspiraciones y concepciones angelicales, segregan esa esfera, fuente de consuelo y esperanza, garantía de que mañana todo será mejor (e igual), y al aislar esa realidad, al darle autonomía, traman la apariencia de una división entre lo mágico y lo cotidiano (Dorfman \& Mattelart, 1978, p. 19).
}

Como en la relación, magistralmente analizada por Williams, del campo y la ciudad, tiene lugar una dicotomía que justifica el orden social. "Bajo la apariencia simpática, bajo los animalitos con gusto a rosa, se esconde la ley de la selva, la crueldad, el chantaje, la dureza, el aprovechamiento de las debilidades ajenas, la envidia, el terror" (Dorfman \& Mattelart, 1978, p. 29). 
En otras palabras, la naturalización de la infancia encubre el mundo real y sus contradicciones, interesadamente oculta, para proyectar en la fantasía la forma material de dominio. En este escenario, las jerarquias culturales están claramente establecidas.

Hay dos tipos de niños. Mientras los metropolitanos son inteligentes, calculadores, cargados de mañas y estratagemas, superiores (cowboys), los periféricos son cándidos, tontos, irracionales, desorganizados y fáciles de engañar (indios). Los primeros son espíritu y se mueven en la esfera de las ideas brillantes, los segundos son cuerpo, materialidad, peso. Unos representan el futuro, los otros el pasado (Dorfman \& Mattelart, 1978, p. 53).

Algo similar a la construcción o representación de género. La mujer aparece en su "rol de humilde servidora (subordinada al hombre) y de reina de belleza siempre cortejada (subordinando al pretendiente). El único poder que se le permite es la tradicional seducción, que no se da sino bajo la forma de la coqueteria" (Dorfman \& Mattelart, p. 35). Entre Blancanieves y la Bruja, la factoría Disney produce una representación restringida de la feminidad. El paternalismo que proyecta el discurso de las historias imaginadas se torna, como es lógico, en patriarcado y se realimenta con el dominio de clase y cultural. Para deconstruir tal dominación, es preciso por lo mismo ligar los conectores ideológicos en el frente cultural de alianzas, disputas y construcción de contraesfera pública que tienen lugar con las jerarquías culturales. Una idea presente en este y otros ensayos de la época en plena década de los setenta.

Habrá quien piense en este texto y la celebración del 50 aniversario de su edición en términos nostálgicos, pero la vigencia de dicha obra va más allá del alcance e impacto obtenido en su momento, en la medida que el ensayo hace una inteligente articulación entre estructura de la información, agencia e imaginario radical. En palabras de Schmucler, "la relación estructura / superestructura mantiene un vínculo bastante más estrecho que el vulgarizado por un pensamiento que, aunque se quiere revolucionario, repite los gestos de un positivismo rigurosamente mecanicista" (Dorfman \& Mattelart, 1978, p. 3). Esta discusión teórica ya la hemos abordado en Marxismo y Comunicación, y plantea el reto de la llamada guerra cultural, el 
papel de la academia y los intelectuales en la era del llamado Capitalismo Cognitivo. Y esto fue lo novedoso del ensayo: abordar el frente cultural de la lucha ideológica, a la que volvemos en la actualidad. Y no solo porque, como vivieron los autores hace cincuenta años, sigue en cuestión toda crítica como un ataque a la libertad de prensa en Chile, España o Venezuela, sino porque la centralidad de la disputa ideológica nos obliga a mirar en la historia la experiencia de las luchas culturales para acometer los retos del presente.

\section{Un relato redivivo en forma de plataforma}

Si el Tío Rico afirma en todo momento su privilegio según la ética protestante del capitalismo, como signo divino, abogando por golpes de suerte, hoy los llamados golpes blandos ilustran hasta qué punto las bases mediáticas hacen posible esa acumulación naturalizada de forma planificada. El discurso del azar que permea la ilusión de la fortuna en la clase media que se moviliza contra el PT en Brasil empieza con las fantasías ilustradas por la industria cultural y se materializan, en lo concreto, en la comunicación política hoy ampliada con la penetración en forma de plataforma de pago por visión. En este momento, Disney llega a todos los hogares con la oferta de la industria Marvel, asumiendo incluso cierto ambiguo discurso antagonista de los superhéroes populares de la cultura comic. En este escenario releer el clásico de Dorfman y Mattelart no tiene otro sentido que volver a pensar la batalla comunicacional, los tigres de papel como ironizara Chomsky en "Los guardianes de la libertad" a propósito del rol de los medios en el orden internacional. Un ejercicio, como advierte Pedro Santander, que apunta a identificar los frentes culturales actualizando la memoria de las luchas por la democracia del sistema informativo: frente a la inequitativa concentración de la estructura de la propiedad, la intervención irregular o encubierta de los medios corporativos globales, en la fase actual de restauración autoritaria, que es posible gracias al control de las redes digitales (Santander, 2020). El objetivo en fin no es otro que disputar la hegemonía empezando por cuestionar el orden distópico que nos proyectan a diario. Más aún cuando sabemos que: 
- La disputa de la hegemonía por el bloque dominante significa un reordenamiento de las correlaciones de fuerza entre el neoliberalismo convencional y la salida autoritaria a la crisis de acumulación capitalista con la emergencia de la ultraderecha: de Trump a Bolsonaro.

- La lucha de clases, en guerra abierta, tiene en los medios un dispositivo de dominio adecuado a los intereses del capital financiero como ya aconteciera en el primer tercio del siglo $\mathrm{xx}$, con la diferencia de un mayor nivel de concentración y dominio local y, particularmente, global.

- La disputa al interior del campo simbólico abre nuevas brechas comunicacionales para el antagonismo y la reconstrucción de un horizonte emancipatorio de la izquierda por pensar y construir, en la práctica.

En este sentido, es preciso, y me atrevería a afirmar que hasta urgente, reconstruir nuestra memoria de las derrotas y las luchas desplegadas en el campo de la información y la cultura. En la última década, personalmente, nos hemos dado con todo el empeño posible a esta tarea. De la antología crítica de textos anotada con el profesor Quirós (Quirós \& Sierra, 2016) a la historia de la propaganda y la intervención comunicacional (Sierra, 2017) pasando por la actual lógica del golpismo mediático. Pero no viene al caso detallar aquí esta historia sino, cuando menos, abrir ventanas e hilos de continuidad para reactivar el pensamiento de la liberación que gracias a la crítica latinoamericana hizo posible el espíritu McBride. Este legado intelectual debe ser actualizado para combatir la dependencia cultural y cuestionar los actuales sistemas extractivistas de datos y colonización tecnológica, hoy sobremanera determinantes con la revolución digital, ante la evidencia de que la tecnología, en el nuevo contexto de la ya formulada sociedad postindustrial o de la información, es capaz de remplazar todos los recursos de poder e incluso organizar golpes de Estado como vimos con el colaboracionismo de Facebook y Twitter contra el gobierno de Dilma Rousseff. La centralidad de la revolución científico-técnica, la llamada cuarta revolución industrial, que hoy vivimos en la actual etapa del modo de producción capitalista no ha inspirado sin embargo a la academia a plantear un diagnóstico en términos de geopolítica de la comunicación respecto a las estrategias de optimización de las estructuras productivas y la necesidad de garantizar el control de esta variable económica al servicio del desarrollo autónomo y equilibrado. 
La dimensión civilizatoria de la tecnología importada que anticipara Celso Furtado vuelve no obstante a la agenda pública no tanto por los debates sobre Economía Creativa como por la constatación en la dialéctica de confrontación entre Washington y Pekín. Recordemos que, en su denuncia de los factores de dependencia tecnológica, los principales avances teorizados por la escuela de la Teoria de Dependencia demostraban, cuando menos -de acuerdo con Sábato y MacKenzie- seis puntos críticos que justificarian hoy dar la vuelta a la lógica dominante en la UIT, formulando de nuevo una propuesta desde el Sur Global. A saber:

- La existencia de obstáculos estructurales al progreso científico-técnico.

- La importancia de la tecnología como mercancía cultural imprescindible para el desarrollo del sistema productivo.

- Las causas económico-políticas de la desagregación tecnológica.

- El desequilibrio y asimetrías en la cooperación y ayuda científico-técnica.

- La creciente importancia de las empresas transnacionales en la producción y comercialización de las nuevas tecnologías.

- La influencia neocolonial en las matrices culturales de los nuevos dispositivos de intercambio y flujo de la información.

Recordemos que la teoría de difusión de las innovaciones aceptada, implícita o explícitamente, por los países periféricos del sistema mundial de información, partía, en lo fundamental, de cuatro supuestos reiteradamente difundidos por los simpáticos personajes de la factoría Disney. A saber: a) Que la tecnología proveniente de los países centrales es la única, la mejor o la más conveniente; b) que la tecnología es neutra, es decir, libre de valores; c) que toda tecnologia moderna es, por definición, la que mejor puede servir para el desarrollo; d) que esa tecnología está suficientemente probada y por lo tanto no hay riesgos en su introducción. De esos lodos los actuales barros del imperialismo distópico en manos de la NSA que hacen posible los golpes blandos y la guerra híbrida contra Nicaragua o Brasil, de Bolivia a Cuba, en forma de guerra permanente que se inicia con la doctrina de GBI en Centroamérica, en plena era Reagan, y hoy se proyecta de forma oculta en las redes de intercambio e interacción social. No es casual por lo mismo que más pronto que tarde los países del llamado Tercer Mundo se opusieran a los principios de la teoría de la 
modernización comunicacional al constatar con mucha preocupación el poder y capacidad de intervención de las industrias transnacionales por el poder de penetración de las nuevas tecnologías objeto de intercambio. Desde entonces sabemos que:

- La aplicación de la tecnología occidental no puede ser aislada de la tradición filosófica en la que esa tecnología ha sido desarrollada.

- La recepción de la tecnología extranjera requiere de una estructura social que pueda acomodarla.

- La tecnología transferida es muy a menudo inapropiada, puesto que en su mayor parte se trata de tecnología que incrementa el consumo privado sin resolver los problemas sociales más urgentes.

- La importación de tecnología extranjera impide el desarrollo de los recursos y el saber-hacer locales.

- La transferencia de tecnología es, además, una tecnología de productos acabados y no del conocimiento que la integra.

Por otra parte, junto a la tecnología, se transfiere la idea de su prescindencia de valores.

Como es sabido, EEUU no aceptaría tales críticas ni las propuestas de reequilibrio de la estructura internacional de información, pese a los evidentes resultados negativos de los planes del PNUD en la materia. La confrontación, académica, vaticinó, como en el caso de Chile, una dialéctica de difícil encaje democrático en el seno de las Naciones Unidas, máxime cuando los principios en liza eran diametralmente antagónicos. En el trasfondo del problema estaba el comando o control del sistema internacional o su desconcentración, que hoy se dirime entre Washington y Pekín en torno al 5G. Y esta es la principal lección que el ensayo de Armand y Ariel nos dejó, como el conjunto de textos de la colección dirigida por Schmucler en Siglo XXI, de acuerdo con la teoría crítica latinoamericana hoy más vigente que nunca. A saber:

- El cambio general de la estructura social constituye el prerrequisito básico para lograr un desarrollo auténticamente humano y democrático.

- Los adelantos tecnológicos en los campos de la agricultura y en otros sectores productivos no solo no conducen necesariamente hacia la obtención 
de este desarrollo, sino que incluso pueden impedirlo al fortalecer aún más a las élites conservadoras dominantes.

- La comunicación no solo es incapaz por naturaleza de generar desarrollo nacional, sino que a menudo actúa en su contra, de nuevo, a favor de las minorias gobernantes.

- La propia comunicación está tan sometida a los arreglos organizativos predominantes en la sociedad, que dificilmente se puede esperar de ella que actúe independientemente como un contribuyente primordial a una profunda y amplia transformación social.

Sociólogos y estudiosos latinoamericanos de la comunicación y de otras regiones del Tercer Mundo inician entonces el debate sobre la necesidad de políticas nacionales de comunicación y cultura que promuevan de verdad formas equilibradas de desarrollo endógeno. De la experiencia chilena al encuentro de mayo de 1976, con el seminario El papel de la información en el nuevo orden internacional, organizado por el Instituto Latinoamericano de Estudios Transnacionales apenas pasan menos de tres años. El suficiente tiempo para constatar, tras la discusión sobre Disney, la necesidad imperiosa de desarrollar mayores esfuerzos de investigación con el fin de favorecer una clara conciencia sobre el papel de la información y la participación informada de la comunidad dentro de los esquemas integrales de desarrollo humano, más allá de cualquier reduccionismo economicista. La exigencia del NOMIC nace de hecho estrechamente ligada a las necesidades de un Nuevo Orden Económico Internacional en virtud de la demanda de soberanía por parte de los países del Tercer Mundo, que comenzaron a plantear el control de los recursos naturales según un modelo de crecimiento y desarrollo endógeno. Como comenta Schiller, las políticas de comunicación representan, en este sentido, una lucha por superar la dominación externa, donde el poder reside fuera de la comunidad nacional; y la dominación interna, donde el poder es ejercido por una capa nacional dominante. Más aún, las políticas de comunicación y cultura van a ser concebidas como un ejercicio de soberanía cultural en función de los intereses comunitarios. Soberanía e interdependencia son, por lo mismo, los ejes conceptuales del Nuevo Orden Económico Internacional. En la práctica, este giro ideológico significaría un mayor dinamismo de las Políticas Nacionales de Comunicación, a partir 
de nuevos principios estratégicos desde la tradición intelectual emancipadora que la colección de Siglo XXI proyecta remarcando la politicidad, como hemos visto, de la mediación:

- El análisis de los procesos de comunicación de base como plataforma de acceso a la participación popular en el sistema comunicativo.

- La intensificación de los estudios sobre experiencias de comunicación grupal.

- El análisis de la comunicación comunitaria como una modalidad de comunicación integral transformadora.

- Y el estudio de las relaciones entre los medios masivos y las tecnologías tradicionales de educación y cultura en las políticas de desarrollo.

Las recomendaciones emanadas de la reunión de Costa Rica no sólo fueron orientativas de la demanda de un intercambio internacional de información más justo y equilibrado, sino que también constituían las primeras medidas para garantizar el acceso y participación en los medios de todos los miembros y grupos de la sociedad. El texto y las recomendaciones de San José no eran, por tanto, como nos recordaría en persona Luis Ramiro Beltrán, tan sólo documentos históricos. Como bien señalara Elizabeth Fox, debajo de la preocupación central por las políticas nacionales de comunicación había preocupaciones nuevas, como el surgimiento de la comunicación alternativa o la necesaria coordinación regional de las PNC en la búsqueda no conseguida por ejemplo en UNASUR de nuevos procesos de integración regional. Esto naturalmente es historia, y con razón no podemos enfrentar el capitalismo de plataformas sin aprender las lecciones de Chile a San José o la Cumbre Mundial de la Información. El sentido de una lectura a contrapelo de la historia de un ensayo como Para leer el Pato Donald no es otro que conquistar la libertad. En palabras del Director General de la UNESCO, hemos de aprender de anteriores experiencias cómo pueden

reorganizarse las relaciones de intercambio, los flujos de información y las formas de concertación en función de una necesidad primaria, la de permitir que cada pueblo determine su propia via de desarrollo con el respeto de la de los demás, y que todos los pueblos se ayuden mutuamente, es decir, que se enriquezcan los unos a los otros (M`Bow, 1980, p. 5). 
La historia acontecida posteriormente tras el informe McBride y el ciclo de luchas en materia de comunicación del pensamiento antagonista es por todos conocida y ha sido ampliamente reseñada en Chasqui, en Comunicación y Cultura y diversos foros internacionales, incluida la propia ULEPICC. Pero no vamos a dar cuenta de ello ahora. Tienen en la bibliografia algunos aportes generales, en particular desde la perspectiva marxista. Sí conviene apuntar, aunque de forma sucinta, algunos elementos retóricos y discursivos que tuvieron en contra del documento "Un solo mundo, voces múltiples", como también en contra del ensayo de Mattelart y Dorfman. Conviene recordarlos en la medida que los mismos tópicos fueron replicados, en lo esencial contra las políticas nacionales que tuvieron a bien aplicar los gobiernos de progreso en la región, excepto el de Lula, durante la década ganada, con los resultados por todos conocido.

Del encuentro de Talloires a los golpes mediáticos, cabe observar que sigue prevaleciendo contra toda reforma democrática de los medios lo que Reyes Matta denunciara como contraofensiva conservadora en dos frentes:

- Descalificación de los acuerdos multilaterales y del consenso internacional a favor de las acciones de carácter bilateral que en este siglo se tradujo en los bloqueos de los gobiernos conservadores de Colombia y Paraguay de toda iniciativa supranacional y de cooperación en la materia en espacios como UNASUR.

- Estrategias de presión articuladas entre gobiernos y sectores privados para legitimar el principio del libre flujo, ya no sólo en beneficio de la circulación de noticias, sino también de la publicidad y las tecnologias desarrolladas por las grandes corporaciones transnacionales de la electrónica y la industria informática, al tiempo que se ha venido desplegando una permanente campaña de denuncias internacionales en favor de la libertad de prensa contra los procesos democráticos en Venezuela, Bolivia o Cuba ocultando en la prensa internacional que donde se persiguen y asesinan periodistas es siempre en Colombia, México u Honduras. El rol coordinado de la SIP, más hoy Open Society o Reporteros sin Fronteras, da cuenta en este sentido de la prevalencia de un lobby poderoso de los intereses corporativos que constituye un obstáculo importante a todo proceso de democratización de la información, 
reforzado con el creciente control y oligopolio de los medios mercantilistas y las plataformas digitales con base en Silicon Valley.

La manifiesta tendencia hacia la transnacionalización intensiva de la comunicación es sintomática desde la politica de roll-back de la era Reagan de la naturaleza del sistema, cuya reestructuración prácticamente imposibilita, a priori, cualquier regulación cultural a través de las leyes y las definiciones disponibles. A este respecto cabe advertir que al ignorar las estrechas relaciones entre la banca y las nuevas ramas de la industria cultural (informática y telecomunicaciones), el NOMIC nunca había considerado lo suficiente el potencial opositor del capital financiero a una reestructuración equilibrada de los sistemas internacionales de comunicación. Por otra parte, el debate sobre la demanda del Tercer Mundo por un nuevo orden internacional para la información se había caracterizado, en términos generales, por la omisión de aspectos relevantes que afectaban al desequilibrio informativo. Así, por ejemplo, los delegados participantes en la XX Conferencia General de la UNESCO eludieron el análisis de la estructura de propiedad económica de los nuevos medios y de la concentración de los mercados internacionales, que los países receptores de nuevas tecnologías habian favorecido -vía financiación indirecta- a través de los interesados programas de comunicación educativa transnacional como hoy, en buena medida, las regulaciones de Argentina, Bolivia o Ecuador dejaron al margen la función estratégica de los operadores de la nueva economía digital de la información. La reducción del debate del NOMIC al desequilibrado flujo de noticias impidió, entre otros muchos aspectos, afrontar el problema preocupante de la producción y distribución de ciencia y tecnologia, que para entonces había adquirido una dimensión internacional y hoy de hecho se torna central si hablamos de alternativas democráticas. Todo ello, por supuesto, en relación con el sistema dominante de la estructura privada de información, cuyo análisis ignorara, como hemos señalado, el Informe MacBride, en un contexto de desregulación acelerada del sector cuya influencia sería decisiva para la penetración de la industria cultural en la década de los ochenta, por un lado por la financiarización de los medios y, de otra parte, por la importancia del factor tecnológico que ahonda en la consabida dependencia de la renta tecnológica que claramente había anticipado la teoría de la dependencia. En este escenario, el reto que nos 
queda definir en adelante es pensar un horizonte de progreso desde nuevas realidades relativas por ejemplo al papel de la OMPI y las politicas de Sociedad del Conocimiento con las que actualizar la crítica del universo fantástico de la factoría Disney y sus epígonos.

\section{Una agenda por/venir}

Ya sabíamos que la información es poder y que la captura del código es central en el nuevo régimen de mediación social, pero solo hoy que Wikileaks revela las formas de operación y control de la CIA, la mayoría de la población empieza a ser consciente de la era Gran Hermano. Una de las conclusiones más evidentes de los estudios sobre las formas de hegemonía en la comunicación mundial es, precisamente, la imperiosa necesidad del sistema de comando integrado de imponer y propiciar la devastadora lógica de dominio, o seguridad total, colonizando la esfera pública y extendiendo la política de la información de las "bellas mentiras" como relato único y verdadero de los acontecimientos históricos. Y ello, incluso, a condición de planificar y producir masivamente programas de terror mediático y militar para cubrir los objetivos imperiales, anulando todo resquicio de crítica y pluralismo informativo en la comprensión de los problemas fundamentales de nuestro tiempo. De aquí la necesidad de una mirada sediciosa sobre la política informativa que guía y proyecta los intereses creados del Imperio. Sólo si subvertimos nuestra posición de observadores y hacemos un sereno y agudo análisis sobre las formas de producción del consenso en las democracias occidentales, tal y como lo hace en su libro "Un mundo vigilado" Armand Mattelart, podremos entender cómo en la reciente historia existe una delgada línea roja, un hilo histórico que vincula las formas de gestión de la opinión pública del modelo angloamericano con el sistema de propaganda de Goebbels, una lógica instrumental que liga el régimen fascista con la voluntad de poder del gobierno imperial, a Dovifat y la dirección de la opinión pública con Lippmann y la producción del consentimiento, y la política de terrorismo y delaciones nazi, con la red de inteligencia y videovigilancia global que extiende el complejo industrial-militar del Pentágono. Tras la lectura atenta del volumen de Ignacio Ramonet sobre La sociedad vigilada o el trabajo de André Vitalis y 
Armand Mattelart De Orwell al cibercontrol, el campo académico de la comunicación y la izquierda debería replantearse la función que desempeña en este escenario la cultura BIG DATA. Más aún, ¿qué consecuencias tienen los conflictos latentes entre la UE y EE.UU. por el dominio de los flujos de información y el gobierno de Internet? $\mathrm{O}$ ¿en qué sentido podemos hablar de un modelo local de Sociedad de la Información si los principales actores transnacionales de la industria telemática están participados por los intereses estratégicos de la industria estadounidense y el complejo militar del Pentágono? Sabemos que las redes telemáticas están subvirtiendo la democracia, siempre lo han hecho: las redes electrónicas y los nuevos sistemas de comunicación son manifiestamente incompatibles con el diálogo político; la fragmentación y dispersión del espacio público es hoy la norma; el control de las redes a través de programas como Echelon amplía los sistemas de vigilancia y dominio del espacio privado de la comunicación; mientras que la instrumentación mercadológica de la democracia digital en los procesos de elección vacía de contenido público la participación ciudadana.

Decía Debord que la era de la visibilidad y del espectáculo es la era no de la transparencia sino del secreto. En palabras de Zizek, cuando más alienada, espontánea y transparente es nuestra experiencia, más se ve regulada y controlada por la invisible red de agencias estatales y grandes compañias que signan sus prioridades secretas. El empeño por gestionar la opinión pública no es, sin embargo, reciente. Ya el padre de los estudios de opinión pública en Estados Unidos, Walter Lippmann, calificaba como "lamentable proceso de democratización de la guerra y de la paz" la participación ciudadana, a través de la prensa y el debate público, en los asuntos de interés general que conciernen a la organización del Estado y su politica exterior, por lo que, naturalmente, había que procurar fabricar el consentimiento, impedir la mediatización pública por el vulgo en los asuntos estratégicos que deben definir las élites. La llamada guerra contra el terrorismo se basa en este principio y proyecta, en el mismo sentido, un modelo de mediación informativa opaco y concentrado que ha permitido desplegar en las intervenciones contra los llamados "enemigos de la democracia y la paz universales" diversas estrategias de terror planificado. La que hoy denominamos Sociedad de la Información amplifica, de hecho, los dispositivos de poder y normalización de la comunicación como dominio. Por ello, de acuerdo con Zizek, Assange 
representa una nueva práctica de comunismo que democratiza la información. Lo público solo se salvará por la épica de los héroes de la civilización tecnológica. Assange, Manning, Snowden son, como sentencia Zizek, "casos ejemplares de la nueva ética que corresponde a nuestra época digital». Como espía del pueblo, la autonegación de Assange es la épica del héroe que socava la lógica del secreto para afirmar la publicidad por razones geopoliticas y de derechos. Sobre todo del derecho a tener derechos frente al discurso cínico de la Casa Blanca que Wikileaks revela deconstruyendo, punto a punto, documento a documento, la vergüenza de un orden social arbitrario.

Quienes hemos participado en la campaña internacional por la libertad del fundador de Wikileaks sabemos que en esta lucha nos jugamos el futuro de la democracia y los derechos humanos. En la era de la videogilancia global, la defensa de Assange es la protección de todos contra la NSA y la clase estabilizadora del aparato político de terror que trabaja al servicio del muro de Wall Street.

Con frecuencia, sin embargo, los discursos que defienden el papel de la revolución digital en nuestras democracias como una aportación positiva al desarrollo del espacio público más que contribuir al progreso ocultan muchos de los problemas que para nuestra democracia plantea el reto de transformación de los medios digitales. Periodistas, politólogos y responsables públicos coinciden, en este punto, en resaltar, generalmente, el papel revitalizante que la cibercultura tiene hoy para la participación y acceso al espacio público y la gobernabilidad. Pero en todos los casos, estos pronunciamientos y discursos eluden pensar las lógicas y contradictorias formas de integración entre Medios Digitales y Sistema Político. Al hablar de Comunicación y Democracia la inercia común es comenzar reproduciendo, en la galaxia Internet, ideas recurrentes que resultan, por obvias, inoperantes, al incidir, como es el caso de la telefonía móvil, en cuestiones coyunturales, tecnológicas, o insignificantes, de puro vanguardismo tecnológico, carente de criterio, sin capacidad de generación de debate público, ni proposición de enmienda del actual estado de falta de control y déficit democrático que afecta a nuestras instituciones de gobierno y de representación, si hablamos del desarrollo y configuración de la red telemática. Entre la opinión pública, se ha instalado, de hecho, como resultado de décadas de intensivo proceso de 
privatización de las telecomunicaciones, que todo lo relativo a los medios digitales es una opción de consumo, y no un ámbito de derechos y obligaciones.

Los datos de la UNESCO resultan, a este respecto, aleccionadores. Décadas de privatización del espectro radioeléctrico y de la red no solo han agravado las diferencias entre países, regiones y ciudadanos, sino que, además, se han profundizado las desigualdades y desequilibrios en nuestras sociedades, excluyendo sectores vulnerables como mujeres, jóvenes, inmigrantes y minorias étnicas a recursos estratégicos que el mercado no provee en condiciones aceptables.

Las redes tecnológicas y de información pueden, sin duda, llegar a todos los rincones del planeta y potencialmente ser accesibles para todos. Pero, ¿qué tipo de cultura, y sociedad estamos construyendo al amparo de los designios de la inexistente mano invisible del mercado que margina y jerarquiza desde los dispositivos, calidad y formas de acceso y consumo culturales? ¿Es posible la democracia en un espacio público al servicio de intereses privados y en manos de unos cuantos actores globales? En otras palabras, ¿es deseable un sistema cultural dependiente de nuevos medios de extensión tecnológica del conocimiento sin control democrático ni fiscalización social? La respuesta parece obvia. Cuando hablamos de democracia, acceso y participación ciudadana en los nuevos medios digitales cabría recordar que la apertura de las redes es limitada y tiene lugar en un proceso de intensiva concentración de poder por el que el sector público es paulatinamente desplazado para convertirse en proveedora de recursos económicos a las corporaciones transnacionales según el principio de privatización de los beneficios y socialización de las pérdidas. Una modalidad esta que reedita, en la era prometida del acceso con Internet a la cultura, el principio despótico de todo por el pueblo, pero sin el pueblo, ahora además a costa de su dinero, en menoscabo de todo principio racional de igualdad, justicia y proporcionalidad en el diseño del nuevo espacio de captura autoritaria de nuestras democracias. Y es que, en realidad, la ausencia de control democrático sobre los nuevos medios digitales y la imparable privatización de la comunicación y la cultura representa -como explicara Schiller en la gloriosa década neoliberaluna reasignación de recursos de toda la economía y del conjunto de la población a las grandes corporaciones, prevaleciendo el principio del mercado, 
y más exactamente la desigual distribución de poder y de información pública en la toma de decisiones. Por ello, pensar la democracia en la era Internet, es algo más que acceder al consumo y la información en red, significa cuando menos discutir públicamente:

- El papel de los poderes públicos en el diseño, distribución y consumo de los nuevos canales tecnológicos.

- La extensión del dominio público y la defensa de la información y el conocimiento como bienes comunes frente a la imposición del derecho de propiedad intelectual.

- El principio de pluralismo y la regulación de contenidos y estructura de propiedad de los sistemas hiperconcentrados que hoy se imponen en la Sociedad Global de la Información.

- Y la defensa del código abierto para el desarrollo industrial, autónomo y equilibrado de la red Internet.

De otro modo, por más que se extienda comercialmente el consumo de Internet y se haga realidad el principio de Servicio Universal, no es posible hablar, en verdad, de un renacimiento y cualificación de nuestras democracias si no se asumen, en la práctica, tales preceptos. Por ello, al fin de vislumbrar alternativas democráticas y modelos emergentes de resistencia social en la aplicación de los derechos de acceso libre y abierto a la información y al conocimiento, a la ciencia, a la cultura, al software y hardware libres, a las TIC, la conectividad y accesibilidad, y distintos recursos educativos orientadas al desarrollo de los bienes comunes (el procomún) y saberes ancestrales, las lecciones de lo vivido desde la crítica a la industria Disney al Informe McBride admite nuevas lecturas y deben siempre ser recordadas. Toda una oportunidad que ha de ayudarnos a seguir proyectando utopias de futuro sin olvidar la historia de este proceso para evitar repetir nuevos capítulos sobre la democratización de la comunicación ahora en forma de farsa o sainete.

Somos conscientes, en palabras de $\mathrm{M}^{`}$ Bow, que la alternativa sigue siendo Socialismo o Barbarie: "una sola alternativa: hacer los cambios indispensables entre el desorden y la guerra, o de manera concertada y pacífica" (M`Bow, 1980). Se lo debemos a quienes como Ariel Dorfman y Armand Mattelart nos antecedieron en su empeño por mostrar el montaje cultural del ratón Mickey. 
Hemos de honrar con la virtud del compromiso intelectual la obra de quienes tanto lucharon por la utopía. Porque fueron somos y porque somos y tenemos memoria, seremos. Es la gran lección del viejo topo. Toca pues volver a los frentes culturales. No otra función intelectual es más perentoria que ampliar los espacios de esperanza, articulando compromiso, reflexividad crítica y militancia para una Comunicología como Ciencia de lo Común. Aquí y Ahora.

\section{Referencias}

Beltrán, L.R. (1974). Informe para la reunión de expertos sobre la Panificación y las Politicas de Comunicación en América Latina. París, Francia: UNESCO.

Dorfman, A. y Mattelart, A. (1978). Para leer al Pato Donald. Ciudad de México, México: Siglo XXI.

Gifreu, J. (1986). El debate internacional de la comunicación. Barcelona, España: Ariel.

Mastrini, G., Rodríguez, M. y Zarowski, M. (Eds.) (2020). Pensadoras de la comunicación argentina: Margarita Graziano. Aníbal Ford y Héctor Schmucler. Ciudad Autónoma de Buenos Aires, Argentina: Universidad Nacional de General Sarmiento.

M`Bow, A. (1980). Por un diálogo nuevo entre las naciones. Madrid, España: Club Amigos de la UNESCO.

Preston, W. R., Herman, E. y Schiller, H. I. (1989). Hope \& Folly. The United Stares and UNESCO: 1945-1985. Minneapolis, United States: University of Minnesota Press.

Quirós, F. y Sierra, F. (2016). El espiritu McBride. Neocolonialismo, comunicación-mundo y alternativas democráticas. Quito, Ecuador: CIESPAL. 
Reyes Matta, F. (1982). Información y desarrollo bajo

la contraofensiva Reagan. Comunicación y Cultura, (7),51-63.

Santander, P. (2020). La batalla comunicacional. Defensa, ataque y contrataque en América Latina. Caracas, Venezuela: Editorial el perro y la rana.

Schiller, H. (1997). La diplomacia de la dominación cultural y la libre circulación de información. Analisi, (10/11), 76-77.

Sierra, F. (2002). Comunicación, educación y desarrollo.

Sevilla, España: Comunicación Social Ediciones.

Sierra, F. (2017). La guerra de la información. Estados Unidos y el imperialismo en América Latina. Quito, Ecuador:

Centro Internacional de Estudios Superiores de Comunicación para América Latina (CIESPAL).

Sierra, F. (Ed.) (2019). Teoría del valor, comunicación y territorio. Madrid, España: Siglo XXI.

Sierra, F. (2020). Marxismo y comunicación. Madrid, España: Siglo XXI.

UNESCO (1972). Declaración sobre los principios rectores de las transmisiones por satélite para la libre circulación de información, la difusión de la educación y la intensificación de los intercambios culturales. Doc. A/AC 105/109.

UNESCO (1975a). Seminario sobre Politicas Nacionales de Comunicación en América Latina y el Caribe. París: UNESCO.

UNESCO (1975b) Reunión de expertos en el intercambio de noticias en América Latina. París, Francia: UNESCO. 
UNESCO (1976). Informe Final de la Conferencia

Intergubernamental sobre políticas de Comunicación

en América Latina y el Caribe. San José de Costa Rica.

$\mathrm{COM} / \mathrm{MD} / 38$. París, Francia: UNESCO.

UNESCO (1978a). Declaración sobre principios fundamentales para que los medios de comunicación contribuyan a reforzar la paz y el entendimiento internacional, para la promoción de los derechos humanos y para acabar con el racismo, el apartheid y la guerra. (IV.C.3). París, Francia: UNESCO.

UNESCO (1980a). Conferencia Intergubernamental sobre Politicas de Comunicación en África, Yaundé, Camerún, 22-27 de Julio de 1980; Informe final doc. CC/MD/46. París, Francia: UNESCO.

UNESCO (1982). Informe Final de la Conferencia Mundial sobre Politicas Culturales (MONDIACUlT) Doc. 4XC/4. Ciudad de México, México: UNESCO.

UNESCO (1983). Actas de la Conferencia General. Comisión IV. La Comunicación al servicio del Hombre. Gran Programa III. París, Francia: UNESCO.

Zarowsky, M. (2019). Comunicación de masa en Siglo XXI Argentina: una colección orientada por Héctor Schmucler. Revista Internacional de Comunicación y Desarrollo, 3(10), 22-31. http: / / dx.doi.org/ 10.15304/ricd.3.10.5835

Zarowsky, M. (2020). Héctor Schmucler. Izquierdas, vanguardias, comunicación. En G. Mastrini, M. G. Rodríguez y M. Zarowsky (Eds.), Pensadoras de la comunicación argentina: Margarita Graziano. Aníbal Ford y Héctor Schmucler. Ciudad Autónoma de Buenos Aires, Argentina: Universidad Nacional de General Sarmiento. 